\title{
PULMONARY RESISTANCE AND METHODS OF HUMIDIFICATION IN ACUTE PULMONARY FAILURE ${ }^{\circ}$
}

\author{
Michael D. Cooke, $\nmid$ and H. Barrie FaIrley
}

AEROSOLIZED MISTS have been shown to increase airway resistance in conscious spontaneously breathing normal subjects and patients with airway disease, ${ }^{1}$ and inconsistently in normal anaesthetized patients. ${ }^{2,3}$ The increase in resistance is reversible with beta-stimulating bronchodialators, ${ }^{2}$ halothane, and ketamine ${ }^{4}$ and may be prevented by prior administration of isoproterenol. ${ }^{1}$ Atropine is inactive in preventing or correcting these changes ${ }^{1,5}$ and the mechanism is probably a bronchoconstrictive effect secondary to irritation.

Since nebulized mist is frequently used in association with mechanical ventilation for acute pulmonary failure we have extended the previous studies to this set of circumstances.

\section{METHODS}

Ten clinically stable patients with acute pulmonary disease with an Ohio 560 ventilator in the assist/control mode. Tidal volume was constant throughout the study in each patient and ranged between 10 and $15 \mathrm{ml} / \mathrm{kg}$. A Bennett Cascade and a Monaghan 670 ultrasonic humidifier (set to maximum output) were arranged in parallel with a two-way tap which would permit either to be included in the circuit. The temperature of the Cascade humidifier was adjusted to produce an in-line temperature near the airway of $35^{\circ} \mathrm{C}$. Each ventilator humidification system was first tested in the laboratory for water delivery, using a mechanical lung model, weighing the humidifiers before and after 30 minutes of continuous use. The ventilator was set to deliver a tidal volume of $800 \mathrm{ml}$ ten times per minute, at inspiratory flow rates of 40 and $80 \mathrm{l} / \mathrm{min}$. The results are shown in Table I.

All patient measurements were made after 15 minutes of undisturbed ventilation. Airway flow and pressure were recorded continuously, using a Fleisch \#2 pneumotachygraph, a Valydyne MP 45 differential transducer and CD15 carrier demodulator for flow and a Harvard Apparatus transducer for pressure. The pneumotachygraph was calibrated with a Fischer-Porter flowmeter. Resistance was calculated using a modification of the method described by Don and Robson. ${ }^{6}$ Since tidal volume and end-expiratory pressure were constant in each patient and each patient

\footnotetext{
-From the Department of Anesthesia, San Francisco General Hospital, and the Cardiovascular Research Institute, University of California, San Francisco.

Supported in part by grants (GM 18470, GM 6300-14) from the National Institute of Health, and by National Heart and Lung Institute SCOR Grant HL-14201.

tCurrent address: Montreal General Hospital.

Address for reprints: Dr. H.B. Fairley, Department of Anesthesia, San Francisco General Hospital, San Francisco, California 94110.

$\ddagger$ Consolidative processes secondary to trauma, infection, cardiac failure, embolism.
} 
TABLE I

Water Delivered EXPRessed in $\mathrm{ml}_{2} \mathrm{O}$ /liter OF Delivered GaS

\begin{tabular}{|c|c|c|c|}
\hline \multicolumn{2}{|c|}{ Cascade } & \multicolumn{2}{|c|}{ Ultrasonic } \\
\hline $40 \mathrm{~L} / \mathrm{min}$ & $80 \mathrm{~L} / \mathrm{min}$ & $40 \mathrm{~L} / \mathrm{min}$ & $80 \mathrm{~L} / \mathrm{min}$ \\
\hline 0.03 & 0.055 & 0.109 & 0.113 \\
\hline
\end{tabular}

served as his own control, lung volume was constant during each comparison. Resistance was calculated from the difference between peak inspiratory pressure and the pressure at the end of a one-second period of zero flow at end-inspiration. This was divided by the end-inspiratory flow rate.

Measurements of resistance were made in each patient at 40,60 and $80 \mathrm{l} / \mathrm{min}$, using each humidifier alternately, for 15 minutes, and then repeating the sequence in the reverse order. The results of at least ten respiratory cycles and of two trials with each humidifier were averaged and measurements were only accepted during periods of stable end-inspiratory pressures, as a means of excluding the contribution of changing chest wall activity.

Statistical significance was evaluated by two way analysis of variance. The least significant difference test of significance was then used to compare the difference between mean resistance for the two types of humidification at each flow rate.

\section{RESURTS}

The results are shown in Figure 1 and Table II. Although the resistance during ultrasonic nebulization was usually greater, this was not consistently the case and there was no significant difference in the regressions calculated from data obtained with each humidifier or between resistances obtained at each flow rate with the two humidifiers. In an attempt to determine whether those patients with the most airway resistance differ from others, the effect on resistance of the two humidification systems was compared in the five patients with the highest resistance values at $40 \mathrm{l} / \mathrm{min}$, i.e., those in whom the difference between peak and end-inspiratory pressures was greater than $10 \mathrm{~cm} \mathbf{H}_{2} \mathrm{O}$. Resistance was not significantly different (between humidifiers) at any flow rate in this group.

\section{Discussion}

The method employed to assess changes in pulmonary resistance includes all lung-thorax resistive components, including the tracheal tube and provides values which may be difficult to interpret as absolute measures of resistance. However, since recordings were only made during stable periods, as judged by constant endinspiratory pressures, and at constant ventilatory circumstances, we believe that the differences between resistances are indicative of changes in pulmonary resistances due to difference in humidification system.

The volume of water delivered by the two types of humidifier differed by a factor which varied from 3.7 at the lowest flow rate to approximately 2 at the 


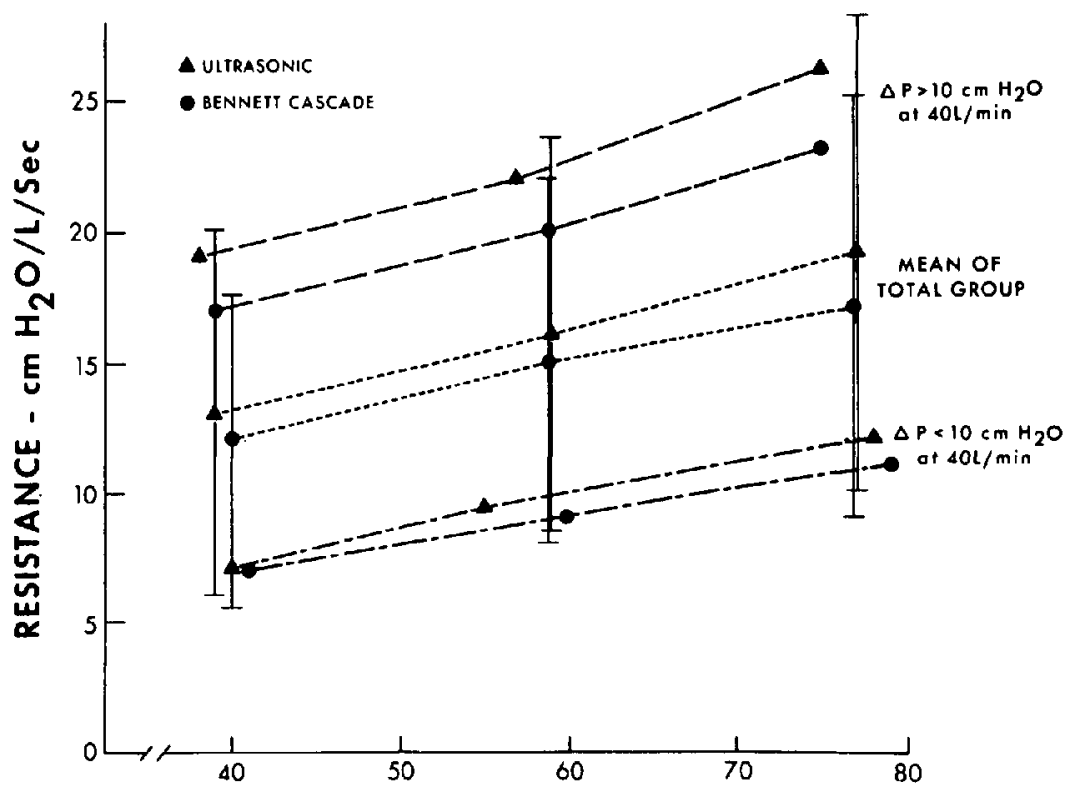

INSPIRATORY FLOW L/min

Frgure 1. Mean resistance as a function of inspiratory flow rate for all ten patients (dotted lines), those with differences between peak and plateau pressures of more than $10 \mathrm{~cm} \mathrm{H}_{2} \mathrm{O} l / \mathrm{min}$ (dashed lines) and less that $10 \mathrm{~cm} \mathrm{H}_{2} \mathrm{O}$ (dots and dashes). Standard errors are shown only for the means obtained from all ten patients.

TABLE II

Pllmonary Resistance (mean $\pm \mathrm{SE}$ ), expressed in $\mathrm{cm} \mathrm{H}_{2} \mathrm{O} / \mathrm{L} / \mathrm{Sec}$

\begin{tabular}{|c|c|c|c|c|c|}
\hline \multicolumn{3}{|c|}{ Cascade } & \multicolumn{3}{|c|}{ Ultrasonic } \\
\hline $40 \mathrm{l} / \mathrm{min}$ & $60 \mathrm{l} / \mathrm{min}$ & $80 \mathrm{l} / \mathrm{min}$ & $401 / \mathrm{min}$ & $60 \mathrm{l} / \mathrm{min}$ & $801 / \mathrm{min}$ \\
\hline $12.0 \pm 2.1$ & $14.8 \pm 2.24$ & $17.2 \pm 2.62$ & $13.2 \pm 2.27$ & $16.1 \pm 2.39$ & $19.0 \pm 2.77$ \\
\hline
\end{tabular}

highest. This is to be expected, since ultrasonic humidifiers deliver water as opposed to water vapour. Air fully saturated with water vapour at $37^{\circ} \mathrm{C}$ contains $0.044 \mathrm{gm} / 1$ of water. The values for water delivered by the Bennett Cascade humidifier (Table I) reflect the interaction of the temperature of the humidifier and the flow rates through it. The temperature was set above $37^{\circ} \mathrm{C}$ to offset the effects of cooling and condensation in the delivery tubing. We considered the possibility that bronchoconstriction secondary to inspired water droplets might be dose-dependent. However, the volumes of water delivered by the systems used by other investigators were $3.5,{ }^{1} 1.5,{ }^{2}$ and $3 \mathrm{gm} / \mathrm{min} .{ }^{3}$ In this study, the volume of water delivered by the ultrasonic nebulizer ranged between 4.36 and $9 \mathrm{gm} / \mathrm{min}$. Therefore, the absence of a significant effect was not related to this aspect of nebulizer performance.

We conclude that ultrasonically generated mists do not necessarily cause a clinically important increase in pulmonary resistance in patients being mechanically ventilated for acute pulmonary failure although in many instances a small increase can be demonstrated. Extrapolating from previous studies, ${ }^{1-5}$ this is most 
probably due to an increase in airway resistance due to bronchoconstriction. These findings differ from those of other investigators studying patients under anesthesia and in the pulmonary function laboratory. However, none of the patients in this study group was being ventilated for exacerbations of chronic respiratory failure and, consequently, these conclusions may not be applicable in that patient group.

\section{SUMMARY}

In order to evaluate the effects of ultrasonic nebulization on airway resistance in respiratory failure, ten patients requiring mechanical ventilation for acute pulmonary failure were each ventilated with two humidification systems, one producing inspired air saturated with water vapour at $35^{\circ} \mathrm{C}$, the other nebulizing water droplets ultrasonically. There was no statistically significant difference in pulmonary resistance at inspiratory flow rates of 40,60 , and $801 / \mathrm{min}$. A separate comparison between humidifiers in those patients with the highest resistances did not reveal any difference in response to method of humidification. In contrast to studies in other contexts, these data fail to show any significant difference, from the standpoint of effects on resistance, in the use of ultrasonic mist humidification during mechanical ventilation for respiratory failure.

\section{RÉSUMÉ}

On a cherché à évaluer les effets de l'humidification des gaz inspirés par nébulisation ultrasonique sur la résistance à l'écoulement du flot inspiratoire dans les voies aériennes de malades en défaillance respiratoire aigue. Chez 10 de ces malades ventilès mécaniquement, on a utilisé deux regimes différents d'humidification: l'un produisant un air inspiré saturé en vapeur d'eau à $35^{\circ} \mathrm{C}$, l'autre un air inspiré véhiculant des gouttelettes d'eau produites par un dispositif à ultra son. Au plan des résistances au courant inspiratoire, on n'a observé aucune différence entre les deux méthodes d'humidification et cela pour des débits de crête de 40,60 et 80 litres/min.

La comparaison des deux méthodes d'humidification chez ces malades qui spécifiquement montraient les résistances les plus hautes au courant inspiratoire n'a pas non plus montré de différence.

Ces données sont en désaccord avec d'autres études qui, il faut le dire, ont été faites dans un contexte différent.

\section{REFERENCES}

1. Cheney, F.W. \& Butrer, J. The effects of ultrasonically produced aerosols on airway resistance in man. Anesthesiology 29: 1099-1106 (1968).

2. Waltemath, C.L., Erbguth, P.H., \& Sunderland, W.A. Increased respiratory resistance after ultrasonic humidification of anesthesia gas. Anesthesiology 39: 547-549 (1973).

3. Cheney, F.W. \& Butler, J. The effects of ultrasonic aerosols on the total respiratory resistance of the intubated patient. Anesthesiology 32: 456-458 (1970).

4. Waltemath, C.L. \& Bergman, N.A. Effects of ketamine and halothane on increased airway resistance provoked by ultrasonic aerosols. Anesthesiology 41:473-476 (1974).

5. Waltemath, C.L. \& Bergman, N.A. Increased respiratory resistance provoked by endotracheal administration of aerosols. Am. Rev, Resp. Dis. 106: 520-525 (1973).

6. Don, H.F. \& RoBson, J.G. The mechanics of the respiratory system during anesthesia. Anesthesiology 26: 168-178 (1965). 